\title{
Effects of Supraphysiological Doses of Steroids on the Left Ventricle of Sedentary Mice: Morphometric Analysis
}

\author{
Érika Larissa Poscidônio de Souza ${ }^{1}$ Rodrigo Leandro Dias ${ }^{1}$ Raíssa Santiago Rios ${ }^{1}$ Tânia Martins Vieira ${ }^{1}$ \\ Bruno Damião ${ }^{1}$ Wagner Costa Rossi Junior ${ }^{1} \quad$ Alessandra Esteves ${ }^{1}$ \\ ${ }^{1}$ Department of Anatomy, Universidade Federal de Alfenas, \\ Alfenas, MG, Brazil \\ J Morphol Sci 2019;36:91-96. \\ Address for correspondence Alessandra Esteves, PhD, Departmento \\ de Anatomia, Universidade Federal de Alfenas. Rua Gabriel Monteiro \\ da Silva, $n^{\circ} 700$, Centro, Alfenas, MG, Brazil, CEP 37130-820 \\ (e-mail: aesteves015@gmail.com).
}

\begin{abstract}
Keywords

- heart

- morphometric analysis

- left ventricle

- steroids

Anabolic androgenic steroids (AAS) are synthetic compounds derived from testosterone, which are widely used in supraphysiological doses by people seeking an aesthetic effect. The objective of the present experiment was to evaluate the possible morphometric changes in the cardiac left ventricle caused by the administration of supraphysiological doses of the anabolic steroids testosterone cypionate and stanozolol in the hearts of young sedentary mice, to serve as a comparative parameter with young mice that were submitted to exercise. We have used 60 hearts of sedentary young Swiss mice, aged $\sim 90$ days old (young-adult), with a body weight between 40 and $50 \mathrm{~g}$. The animals were divided into three groups: the control group, the testosterone cypionate group, and the stanozolol group. For the analysis, 10 distinct sections of the apex, of the middle region, and of the base of the heart were selected, followed by an optical microscope measurement with a $2.5 x$ magnification. The results obtained show an increase in both myocardial thickness and left ventricular cavity diameter in the two groups of male animals in relation to the control group; however, in females, an increase in the thickness of the left ventricular myocardium was observed only for the stanozolol group. These results suggest that the cardiac alterations observed in the present study may be directly related to some signs and symptoms already described in the literature, such as hypertension, arrhythmias, infarction, sudden death, and other cardiovascular diseases.
\end{abstract}

\section{Introduction}

Androgenic anabolic steroids (AAS) are hormones that function in the differentiation, growth, and development of the male reproductive tract, as well as in the development and maintenance of secondary sexual characteristics. However, they also have anabolic effects, stimulating body growth and increasing muscle mass. ${ }^{1}$ AAS are synthetic compounds derived from this hormone, which mimic the anabolic effects of testosterone, while at the same time minimizing androgenic effects. $^{2}$

In the 1950s, the first reports of abuse in the administration of AAS for non-therapeutic purposes by Russian athletes appeared in the literature. ${ }^{3}$ Since then, AAS hormones have

received

August 22, 2018

accepted

January 28, 2019
DOI https://doi.org/

10.1055/s-0039-1681109. ISSN 2177-0298. been used usually by people with good health, in order to increase muscle mass and potency, as well as to provide improvement in their physical condition and appearance. ${ }^{4}$

Illicit long-term and supraphysiologic use of AAS may cause adverse cardiovascular effects, such as pathological hypertrophy, as well as ventricular and atrial arrhythmic events, among which atrial fibrillation is the most frequently observed in bodybuilders. Additionally, several reports of atrial fibrillation suggest a causal link in the use of AAS in athletes. ${ }^{5}$

The compounds selected for the present study are synthetic, commonly used for aesthetic purposes, with testosterone cypionate being one of the most widely used AAS in the market. ${ }^{6}$

One of the mechanisms described in the literature regarding the use of supraphysiological doses is associated with the
Copyright @ 2019 by Thieme Revinter Publicações Ltda, Rio de Janeiro, Brazil
License terms

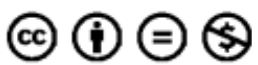


temporary nitrogen retention of ingested proteins, as well as with the competition of receptors of glucocorticoids released during intense exercise, leading to the inhibition of protein catabolism. $^{7}$

Increased erythropoiesis is also a risk factor for erythropoietin stimulation and hepcidin suppression. Erythropoietin is the erythrocyte stimulating hormone, whereas hepcidin is a protein that regulates iron absorption, so the erythropoietin produced is more active due to the higher concentration of serum iron. ${ }^{8}$

Understanding the ease of obtaining anabolic agents, the indiscriminate use of these drugs and their possible side effects, it was proposed to evaluate in a specific and controlled way the effects of supraphysiological doses of these AAS in sedentary mice for comparison with a group of animals treated with the same drugs, but performing physical exercise, in order to obtain accurate information and, with this, to raise awareness, mainly to the generation of young adolescents, about the possible causes and effects of the indiscriminate use of these substances.

\section{Materials and Methods}

For the present experiment, 60 Swiss mice were used (30 males and 30 females) from the Universidade Federal de Alfenas (UNIFAL, in the Portuguese acronym) (Committee for Ethics in Animal Experimentation [CEEA], Universidade Federal de Alfenas, registry number 505/2013). These were housed in boxes containing 5 animals each, and were treated with commercial feed and ad libitum water and kept in a light-dark 12-hour cycle.

The treatment consisted of the intraperitoneal application of two AAS, as follows: Group 1: testosterone cypionate (Deposteron [EMS, São Bernardo do Campo, SP, Brazil]) (0.8 $\mathrm{mg} / \mathrm{kg}$ ); group 2: stanozolol ([Winstrol-Stanozolol Depot, Landerlan, Lambaré, Paraguay]) (1.8 mg/kg), and group 3: physiological solution $(1 \mathrm{ml} / \mathrm{kg}$ ). The animals were treated for 2 months, with doses applied twice a week at 2-day intervals.

After the euthanasia of the animals by means of the halothane anesthetic and the identification of each animal, the thoraxes were opened and the hearts were entirely removed. Finally, the organs were stored in glass containers containing paraformaldehyde $(\mathrm{pH}$ 7.4). They remained immersed in this fixative solution for 24 hours.

The hearts were processed following the standardized histological procedures. The paraffin-embedded samples were cut in a thickness of $7 \mu \mathrm{m}$ in a Yidi microtome ([Jinhua YIDI Medical Appliance CO., LTD, Jinhua City, Zhejiang province, China]) and stained with hematoxylin and eosin (H\&E).

For the morphometric analysis, 10 distinct sections of the apex, of the middle region, and of the base of the heart were selected (-Fig. 1). To measure ventricular cavity diameter, was selected the entire area of ventricular cavity by means of one of the tools of the software Axiovision Version. 4.8.2 (Carl Zeiss Microscopy LLC, Peabody, MA, USA). To measure the myocardical thickness, three areas (anterior, posterior and lateral) were selected and was used the same software for

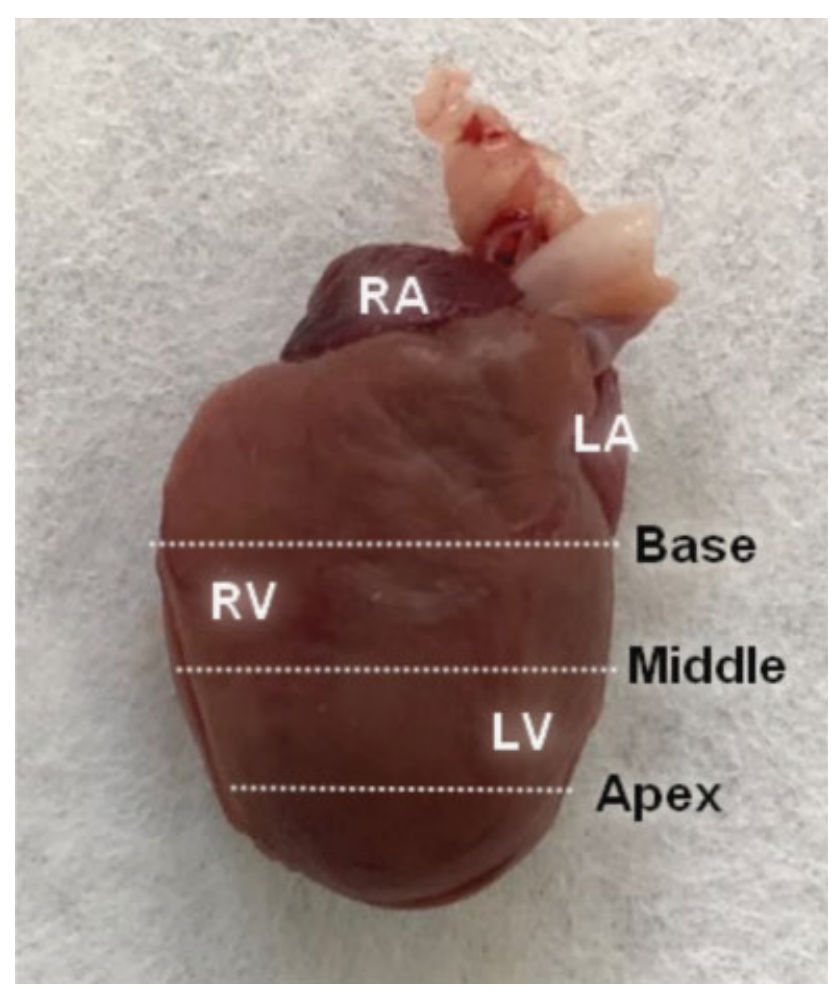

Fig. 1 Heart of a normal mouse demonstrating the regions to be analyzed (white trace): the apex, the middle region, and the base. Abbreviations: LA, left atrium; LV, left ventricle; RA, right atrium; RV, right ventricle.

analysis [Axiovision Version. 4.8.2 (Carl Zeiss Microscopy LLC, Peabody, MA, USA)]. The values were measure in $\mu \mathrm{m}^{2}$.

The analysis was performed using an optical microscope model Axion Scope A1 (Carl Zeiss Microscopy LLC, Peabody, MA, USA) coupled to Axiovision Version. 4.8.2 (Carl Zeiss Microscopy LLC, Peabody, MA, USA) and to the Axiovision 4 Module Interactive Measurement software (Carl Zeiss Microscopy LLC). To capture the selected images, a 2.5x objective lens (Carl Zeiss Microscopy LLC, Peabody, MA, USA) was used (-Fig. 1).

To evaluate the mean values of the left ventricle areas, according to the gender of the mice and to the treatment imposed (research groups), the analysis of variance (ANOVA) was used. When a significant difference $(p<0.01)$ was observed among the groups when comparing different variables, the Tukey test was used to discriminate differences and/or similarities among the evaluated means. ${ }^{9}$

\section{Results}

As shown in the graphics, no significant result was observed in the diameter of the left ventricle cavity of the hearts of female mice in the control group in relation to the treated groups (-Fig. 2A).

However, when analyzing the myocardial thickness, a significant difference was observed, showing a decrease in the myocardial thickness of the stanozolol group in relation to the control group ( $p<0.00001)$, as well as in the group treated with testosterone cypionate in relation to the group treated with stanozolol $(p<0.0001)$. However, when the testosterone 


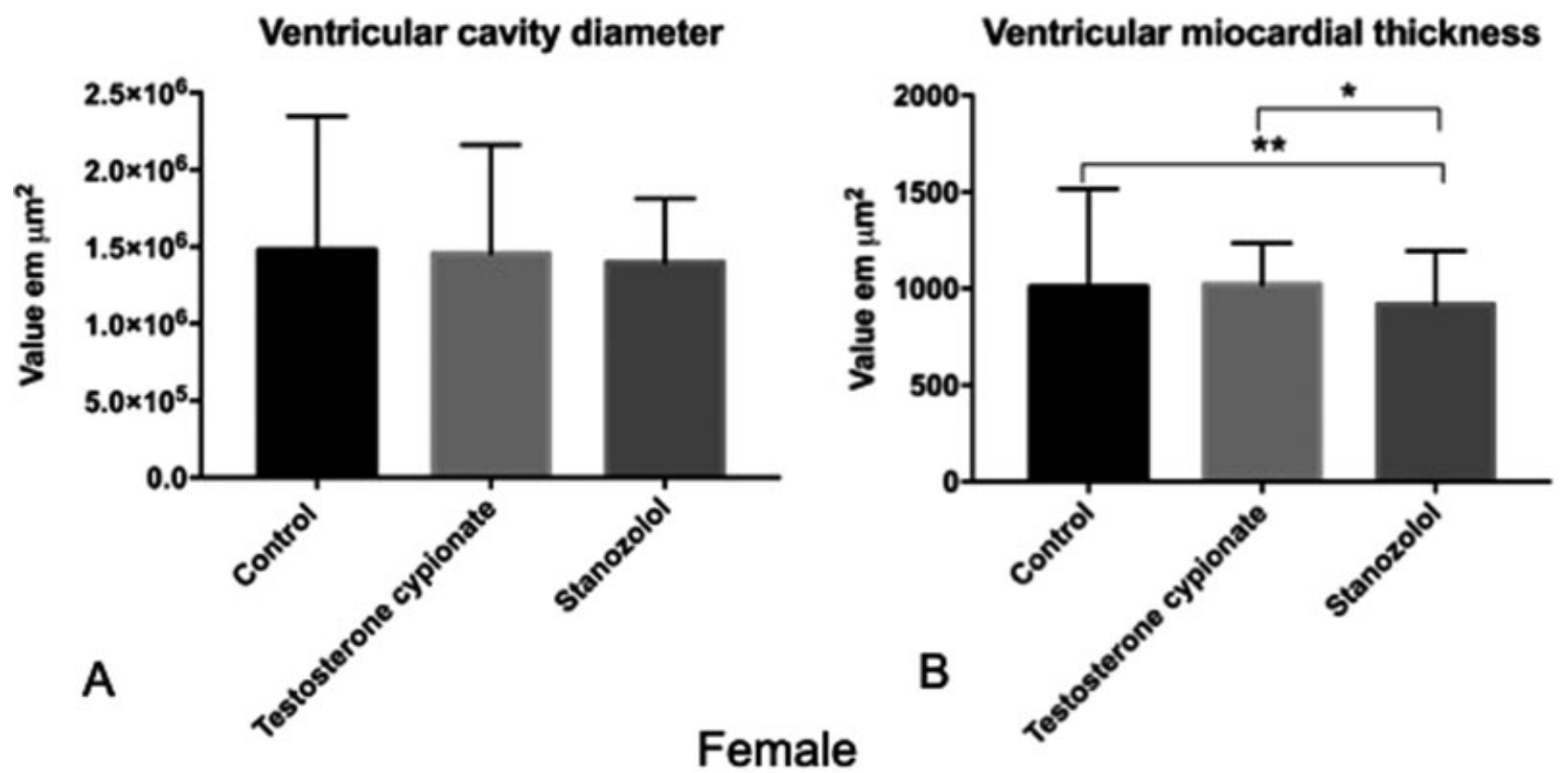

Fig. 2 (A) The graphics demonstrate the nonsignificant difference in the left ventricular cavity diameter of female mice between the experimental groups.(B) Shows the significant difference in the left ventricular myocardial thickness observed between the control group in relation to the group treated with stanozolol (Winstrol Depot) $\left({ }^{* *}\right)$, and the group treated with testosterone cypionate (Deposteron) in relation to the Stanozolol (Winstrol) group $\left({ }^{*}\right)$.

cypionate group was compared with the control group, no statistically significant result was obtained ( $\mathbf{- F i g . ~ 2 B ) . ~}$

When comparing the diameter of the left ventricle in male mice, significant differences were observed, showing that both of the AAS evaluated increased the diameter of the left ventricular cavity, both in the testosterone cypionate group in relation to the control group $(p<0.0001)$, and in the stanozolol group in relation to the testosterone cypionate group ( $p=0.0009)$ ( - Fig. $3 \mathbf{A}$ ).

Regarding the analysis of the thickness of the left myocardial ventricle, the male mice presented significant differences between the control group and the 2 treated groups: testosterone cypionate $(p<0.0001)$ and stanozolol $(p=0.0008)$. A statistically significant difference was also observed

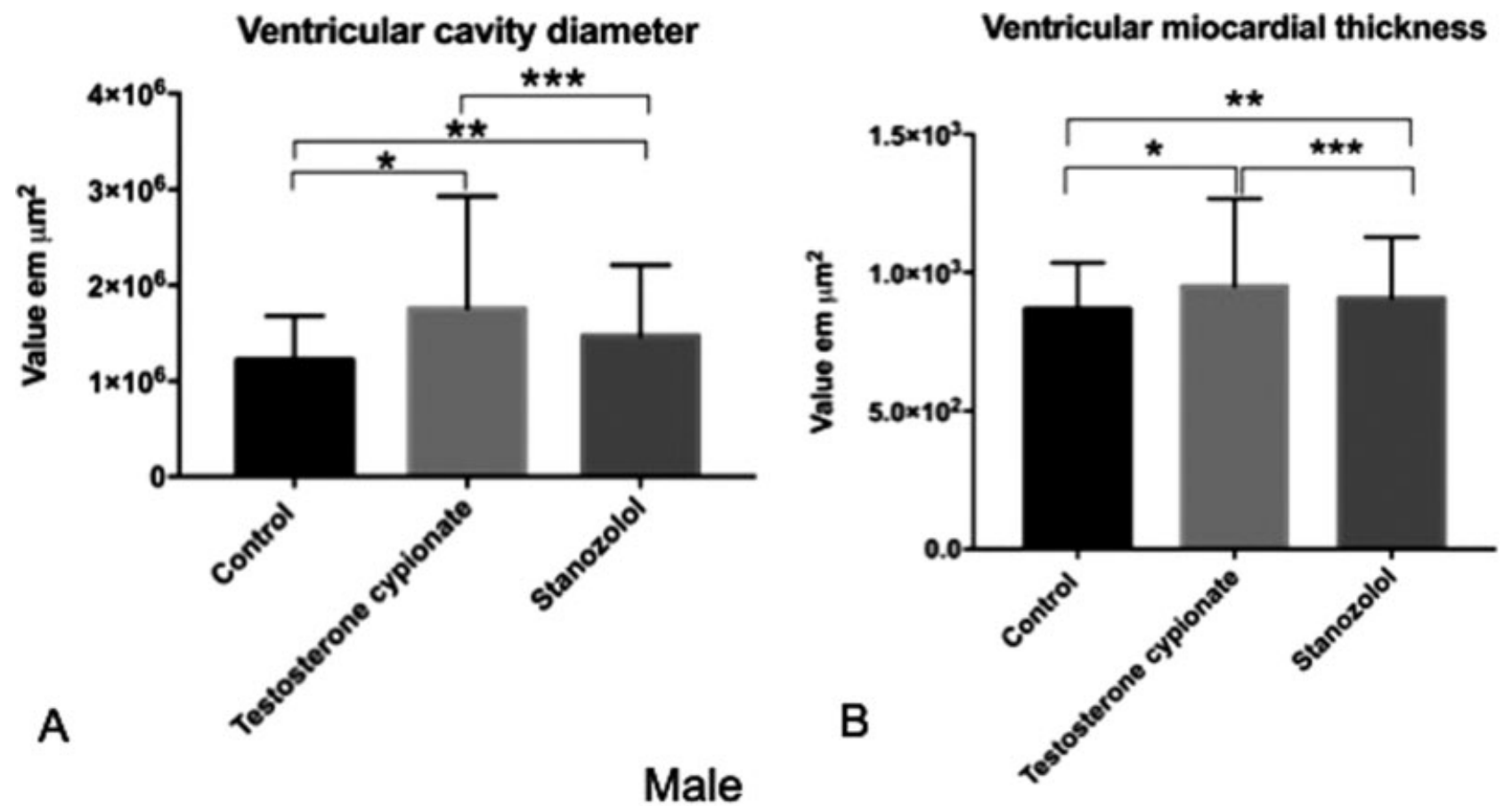

Fig. 3 The graphics show the statistically significant difference found in the left ventricular cavity diameter $(A)$ and in the left ventricular myocardial thickness (B) between male mice in the control group and in the testosterone cypionate (Deposteron) group $\left({ }^{*}\right)$, between the control group and the Stanozolol (Winstrol) group $\left({ }^{* *}\right)$, and between the two groups treated with the different steroids $\left({ }^{* * *}\right)$. 


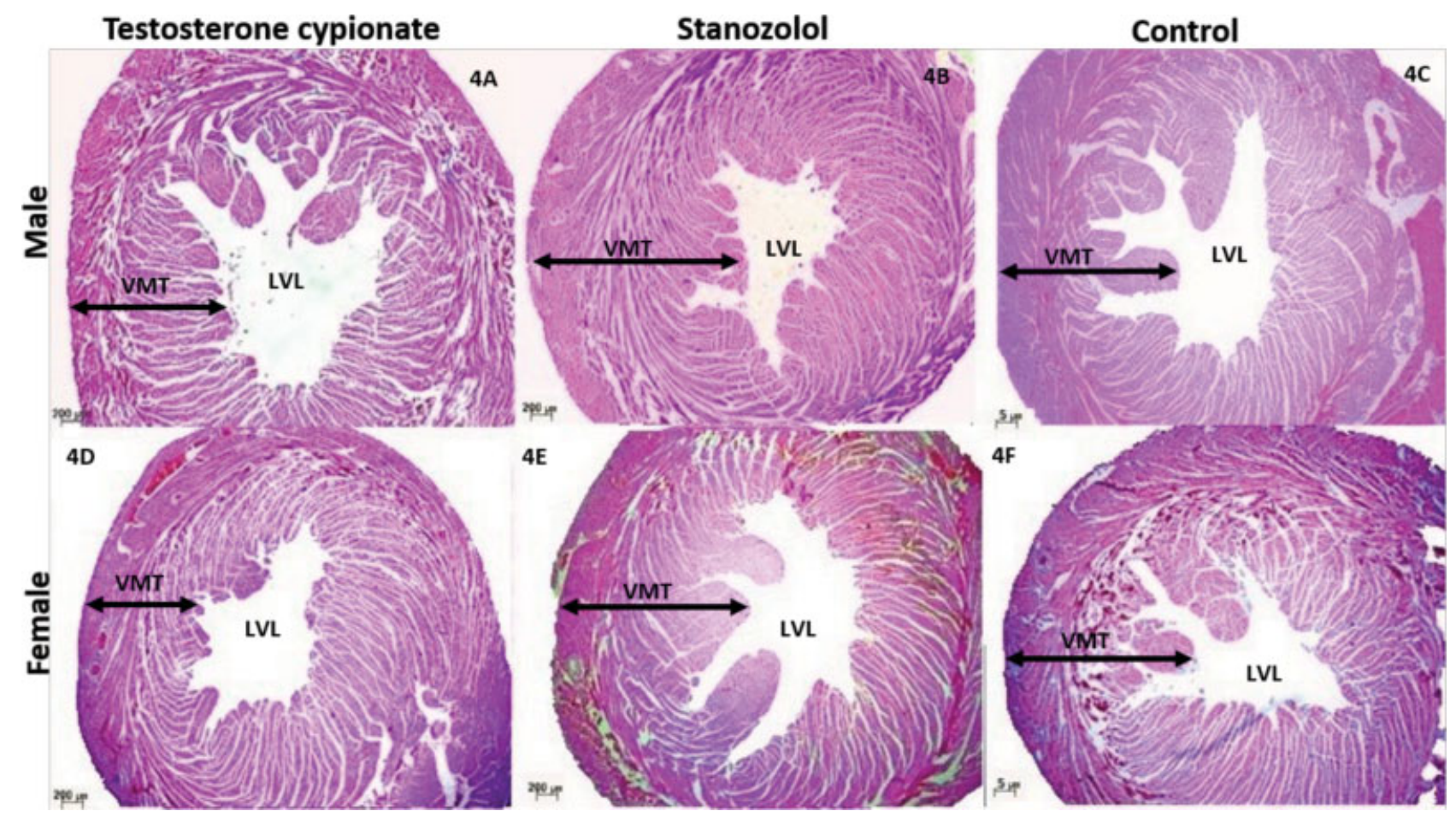

Fig. 4 Histological section of the left ventricles of some of the mice studied, (A) male mouse treated with testosterone cypionate, (B) stanozololtreated male mouse, (C) male mouse in the control group, (D) testosterone cypionate-treated female mouse, (E) stanozolol-treated female mouse, and (F) female mouse in the control group, Abbreviations: LVL: left ventricular cavity; VMT, ventricular myocardial thickness.

between the stanozolol group and the testosterone cypionate group $(p=0.0004)$ ( - Fig. 3B).

-Fig. 4 represents histological section of the left ventricules of some of the male and female mice studied, stained in $\mathrm{H} \& \mathrm{E}$, with a $2.5 \mathrm{x}$ magnification, of all in the groups studied for comparation.

\section{Discussion}

Left ventricular hypertrophy is directly related to increased blood pressure and systemic by compensatory mechanism. High blood pressure is associated with a three to four fold increase in the risk of stroke, fibrillation, and ventricular arrhythmia. ${ }^{10,11}$ This study corroborates the results found Seara et al. ${ }^{15}$, showing a significant increase in myocardial thickness and ventricular cavity diameter, in male mices.

According to literature, the use of nandrolone, another AAS widely used, promotes changes in endothelium of blood vessels, both at the sedentary and exercised female mice, indicating that physical exercise does not decrease the effects caused by AAS, and that sedentary users also suffer significant damage. ${ }^{12}$ Other damages are also described by some authors, which demonstrated increased levels of LDL, HDL, NADPH oxidase in association with ventricular hypertrophy in rats treated with nandrolone, doing or not doing exercises. ${ }^{13,14}$

For Seara et al, ${ }^{15}$ this cardiac hypertrophy is due to the thickening of the posterior wall of the left ventricle and of the interventricular septum in addition to fibrosis, even with discontinuation of the AAS treatment, thus reporting irreversible cardiac damage. And this can occur through several mechanisms, one of which is the increase in cardiac angio- tensin due to the stimulus of the activity of the converting enzyme, and angiotensin II has been related to cardiac remodeling by cellular hypertrophy and collagen deposition.

The studies of Nascimento et $\mathrm{al}^{16}$ showed that the deposition of collagen in cardiac cells can lead to a loss of the contractile function, with increased rigidity; moreover, an increase in the left ventricular systolic pressure has been reported, whereas a decrease in the diastolic function was observed, causing left ventricular isovolumic relaxation failure in rats treated with AAS. This failure in relaxation is one of the major etiological factors of ischemia and heart failure.

The possible increase in the erythrocytes count due to the stimulation caused by these hormones can also be seen as a risk factor because it leads to an increase in blood volume. Consequently, the heart would need more force to pump the blood to the tissues, causing hypertrophy. ${ }^{17}$

The results obtained in this study did not significantly alter the diameter of the left ventricular cavity of female mice, which can be explained by a cardiac and vascular protective effect of the endogenous estrogen, contributing to the maintenance of caliber and myocardial diameter, suggesting a possible compensation mechanism. ${ }^{12,18}$

According to Barp, ${ }^{19}$ the cardiovascular protective effect of estrogen occurs in several ways, such as the stimulation of nitric oxide (NO), which is a vasodilatation gas that prevents platelet aggregation, endothelial leukocyte adhesion, endothelin production, and control of the vascular tone. Another protective factor is that estrogen can decrease cell proliferation in the tunica intima and in the tunica adventitia in the vessel wall, inhibiting protein kinase, which is in line with the results obtained in the present study. 
Another probable hypothesis for the results found in females is the same as reported by Clark, ${ }^{20}$ who states that, unlike testosterone cypionate, stanozolol has the ability to interfere with the production of estrogen by central action, as well as the potential to inhibit the hypothalamus-pituitary-gonadal axis, thus decreasing the production of estrogen, which explains the fact that the myocardial thickness of female mice changes once they no longer have the protective action of the hormone.

In patients with deficiency in testosterone levels, a deficiency of myocardial contraction is noted. In contrast, studies indicate that, at high levels, testosterone can be harmful because it acts directly on androgen receptors, which in turn act on genes that make the transcription of alpha-myosin heavy chain $(\alpha-\mathrm{MHC})$ and of transforming growth factor beta (TGF- $\beta$ ) proteins, which act respectively on atrial contraction and on the control of cell proliferation and differentiation. ${ }^{21}$

The results found by Pirampol et al. ${ }^{21}$ may explain the results found in this study, which present a difference between the studied genders, showing that, in female mice, the use of AAS, such as stanozolol, may decrease the thickness of the left ventricular myocardium, while the results were the opposite in male mice.

The use of AAS causes changes in normal physiological adaptations that occur after exercise, from compen- sated to uncompensated hypertrophy and is related to several pathological processes according to Nascimento and Medei ${ }^{22}$, such as heart failure, reduced tolerance to ischemia, and ventricular dilatation, which can also be demonstrated by the results found in the present study.

The use of AAS causes hypertrophy of cardiomyocytes, and a decrease in capillary density and increased capillary spacing was observed. It is presumed that these alterations affect the supply of oxygen to the myocardium by subjecting it to ischemia. 23

Some researchers report the development of stress and cellular damage caused by the chronic use of AAS. In biochemical tests, it is known that troponin isoenzymes (cTnI) and creatine kinase $\mathrm{MB}(\mathrm{CK}-\mathrm{MB})$ are specific indicators of cell lysis and are elevated in users of anabolic steroids. ${ }^{24,25}$

The heart rate also decreases after exercise, according to dos Santos, ${ }^{26}$ who also reports that this may be an effect of changes in the parasympathetic nervous system, suggesting that these effects may also occur at rest in the case of sedentary mice, due to the changes already mentioned. The decrease in heart rate is a predisposing factor to cardiovascular pathologies.

\section{Conclusion}

The alterations found in the left ventricular cavity and thickness of the left ventricular myocardium allow to conclude that innumerable pathologies, such as vascular and cardiac hypertension, arrhythmias, acute myocardial infarction, and sudden death, may be associated with the findings described in the present study and that, beyond these alterations, it is also suggested that the indiscriminate use of AAS may bring serious risks to the user in relation to general health.
It is possible to see the great importance of studies related to AAS due to the increasing use of these substances in supraphysiological doses for non-medical purposes also by sedentary individuals who believe in the increase of muscular mass without physical effort.

\section{Financial Support}

The authors thank the financial support for accomplishment of this work provided by the Foundation of Support to Research of State of Minas Gerais (FAPEMIG, in the Portuguese acronym - Fundação de Amparo à Pesquisa do Estado de Minas Gerais).

\section{Conflicts of Interest}

The authors have no conflicts of interest to declare.

\section{References}

1 Armstrong JM, Avant RA, Charchenko CM, et al. Impact of anabolic androgenic steroids on sexual function. Transl Androl Urol 2018;7 (03):483-489. Doi: 10.21037/tau.2018.04.23

2 Yu JG, Bonnerud P, Eriksson A, Stål PS, Tegner Y, Malm C. Effects of long term supplementation of anabolic androgen steroids on human skeletal muscle. PLoS One 2014;9(09):e105330. Doi: 10.1371/journal.pone.0105330

3 Cunha TS, Cunha NS, Moura MJCS, et al. Esteroides anabólicos androgênicos e sua relação com a prática desportiva. Revista Brasileira de Ciências Farmacêuticas 2014;40(02):165-179

4 Molero Y, Bakshi AS, Gripenberg J. Illicit Drug Use Among GymGoers: a Cross-sectional Study of Gym-Goers in Sweden. Sports Med Open 2017;3(01):31

5 Akçakoyun M, Alizade E, Gündoğdu R, et al. Long-term anabolic androgenic steroid use is associated with increased atrial electromechanical delay in male bodybuilders. BioMed Res Int 2014; 2014:451520. Doi: 10.1155/2014/451520

6 Lima AP. CARDOSO FB. Alterações fisiológicas e efeitos colaterais decorrentes da utilização de esteroides anabolizantes androgênicos. Revista Brasileira de Ciências da Saúde 2011;9(29):39-46. Doi: 10.13037/rbcs.vol9n29.1252

7 Ferreira UMG, Ferreira ACD, Azevedo AMP, et al. Esteroides Anabólicos Androgênicos. Rev Brasileira em Promoção da Saúde 2007;20(04):267-275

8 Bachman E, Travison TG, Basaria S, et al. Testosterone induces erythrocytosis via increased erythropoietin and suppressed hepcidin: evidence for a new erythropoietin/hemoglobin set point. J Gerontol A Biol Sci Med Sci 2014;69(06):725-735. Doi: 10.1093/ gerona/glt154

9 Alves DM, Silva MSO, Zavan B, et al. Morphometric analysis of mice's ventricular myocardium submitted to androgenic anabolizing steroids use. Journal of Morphological Science 2015;32(01): 33-36. Doi: $10.4322 / \mathrm{jms} .071614$

10 Lip GYH, Felmeden DC, Li-Saw-Hee FL, Beevers DG. Hypertensive heart disease. A complex syndrome or a hypertensive 'cardiomyopathy'? Eur Heart J 2000;21(20):1653-1665. Doi: 10.1053/ euhj.2000.2339

11 Nucci RAB, Tanasov VS, Krause Neto W, et al. Testosterone Administration Alters Hepatic Blood Flow Across Age: Systematic Review of Animal Experimental Studies. J Morphol Sci 2018;35 (02):96-100. Doi: 10.1055/s-0038-1669470

12 Caliman IF, Bernabe CS, de Melo AF Jr, et al. Long-term treatment with Nandrolone Decanoate impairs mesenteric vascular relaxation in both sedentary and exercised female rats. Steroids 2017; 120:7-18. Doi: 10.1016/j.steroids.2017.02.001

13 Tofighi A, Shirpoor M, Ansari MHK, Shirpoor A, Zerehpoosh M. The effect of nandrolone treatment with and without enforced 
swimming on histological and biochemical changes in the heart and coronary artery of male rats. Anatol J Cardiol 2017;17(03): 176-183. Doi: 10.14744/AnatolJCardiol.2016.7333

14 Moreira WF, Scoss DM. Risco do Uso Indiscriminado de Esteróides Androgênicos Anabolizantes na Hipertrofia Muscular. Revista ENAF Science 2016;11(01):371-383

15 Seara FAC, Barbosa RAQ de Oliveira DF, et al. Administration of anabolic steroid during adolescence induces long-term cardiac hypertrophy and increases susceptibility to ischemia/reperfusion injury in adult Wistar rats. J Steroid Biochem Mol Biol 2017; 171:34-42. Doi: 10.1016/j.jsbmb.2017.01.012

16 Nascimento AM, Lima EM, Brasil GA, et al. Serca2a and $\mathrm{Na}(+) / \mathrm{Ca}$ $(2+)$ exchanger are involved in left ventricular function following cardiac remodelling of female rats treated with anabolic androgenic steroid. Toxicol Appl Pharmacol 2016;301:22-30. Doi: 10.1016/j.taap.2016.04.001

17 Unver S, Kavlak E, Gümüsel HK, et al. Correlation between hypervolemia, left ventricular hypertrophy and fibroblast growth factor 23 in hemodialysis patients. Ren Fail 2015;37(06): 951-956. Doi: 10.3109/0886022X.2015.1052945

18 Rosano GMC, Spoletini I, Vitale C. Cardiovascular disease in women, is it different to men? The role of sex hormones. Climacteric 2017; 20(02):125-128. Doi: 10.1080/13697137.2017.1291780

19 BARP. J. 2007. Avaliação do dano oxidativo e função cardiovascular em diferentes modelos de hiperhomocisteinemia: papel protetor do folato e do estrogênio. Porto Alegre: Instituto de Ciências Básicas da Saúde; Universidade Federal do Rio Grande do Sul. 134 p. Tese de doutorado em Ciências Biológicas: Fisiologia
20 Clark AS, Blasberg ME, Brandling-Bennett EM. Stanozolol, oxymetholone, and testosterone cypionate effects on the rat estrous cycle. Physiol Behav 1998;63(02):287-295. Doi: 10.1016/s00319384(97)00443-5

21 Pirompol P, Teekabut V, Weerachatyanukul W, Bupha-Intr T, Wattanapermpool J. Supra-physiological dose of testosterone induces pathological cardiac hypertrophy. J Endocrinol 2016; 229(01):13-23. Doi: 10.1530/JOE-15-0506

22 Nascimento JH, Medei E. Cardiac effects of anabolic steroids: hypertrophy, ischemia and electrical remodelling as potential triggers of sudden death. Mini Rev Med Chem 2011;11(05): 425-429. Doi: 10.2174/138955711795445899

23 Tagarakis CV, Bloch W, Hartmann G, Hollmann W, Addicks K. Anabolic steroids impair the exercise-induced growth of the cardiac capillary bed. Int J Sports Med 2000;21(06):412-418. Doi: $10.1055 / \mathrm{s}-2000-3835$

24 Arazi H, Mohammadjafari H, Asadi A. Use of anabolic androgenic steroids produces greater oxidative stress responses to resistance exercise in strength-trained men. Toxicol Rep 2017;4(04):282-286. Doi: $10.1016 /$ j.toxrep.2017.05.005

25 Karbasi S, Zaeemi M, Mohri M, Rashidlamir A, Moosavi Z. Effects of testosterone enanthate and resistance training on myocardium in Wistar rats; clinical and anatomical pathology. Andrologia 2018;50(03):1-15. Doi: 10.1111/and.12908

26 dos Santos MR, Dias RG, Laterza MC, et al. Impaired post exercise heart rate recovery in anabolic steroid users. Int J Sports Med 2013;34(10):931-935. Doi: 10.1055/s-00321331741 